\title{
ENERGY TRANSFER IN REAL AND ARTIFICIAL PHOTOSYNTHETIC SYSTEMS †
}

\author{
J.C. Hindman, J.E. Hunt and J.J. Katz ${ }^{\ddagger}$
}

Chemistry Division

\author{
Argonne National Laboratory
}

Argonne, IL 60439

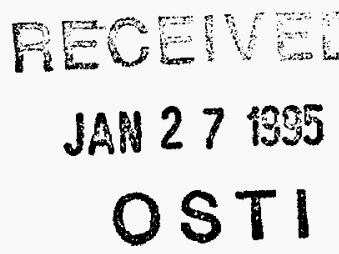

\section{DISCLAIMER}

\begin{abstract}
This report was prepared as an account of work sponsored by an agency of the United States Government. Neither the United States Government nor any agency thereof, nor any of their employees, makes any warranty, express or implied, or assumes any legal liability or responsibility for the accuracy, completeness, or usefulness of any information, apparatus, product, or process disclosed, or represents that its use would not infringe privately owned rights. Reference herein to any specific commercial product, process, or service by trade name, trademark, manufacturer, or otherwise does not necessarily constitute or imply its endorsement, recommendation, or favoring by the United States Government or any agency thereof. The views and opinions of authors expressed herein do not necessarily state or reflect those of the United States Government or any agency thereof.
\end{abstract}

† Dedicated to the memory of Gerhard L. Closs

\$ Author to whom correspondence may be addressed.
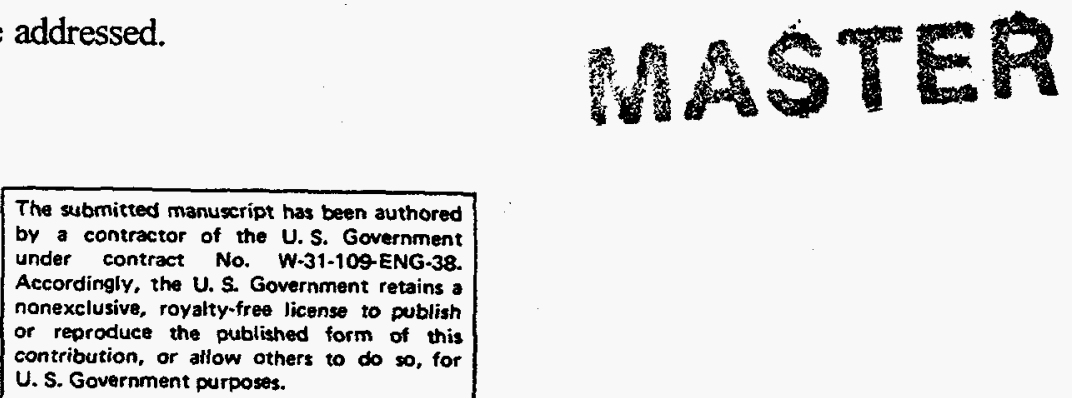


\section{DISCLAIMER}

Portions of this document may be illegible in electronic image products. Images are produced from the best available original document. 
Fluorescence emission from the photosynthetic organisms Tribonema aequale, Anacystis nidulans, and Chlorella vulgaris and from some chlorophyll model systems have been recorded as a function of excitation wavelength and temperature. Considerable similarity was observed in the effects of excitation wavelength and temperature on the fluorescence from intact photosynthetic organisms and the model systems. The parallelism in behavior suggest that self-assembly processes may occur in both the in vivo and in vitro systems that give rise to chlorophyll species at low temperature that may differ significantly from those present at ambient temperatures.

\section{Introduction}

Despite major advances in the understanding of the primary light conversion events in photosynthesis resulting from the successful crystallization of the photoreaction center of photosynthetic bacterid, many aspects of the primary processes of photosynthesis, particularly in green plants, remain obscure. The current consensus has it that charge oxidation and reduction capacity in green plant photosynthesis takes place by serial operation of two photoreaction centers (PSI and PSII), which, like the light-harvesting apparatus, consist of chlorophyll-protein complexes. It is also widely assumed that the anomalous optical properties of in vivo chlorophyll can be attributed to chlorophyll-protein interactions. Further, it is generally accepted that fluorescence originating in the reaction centers or the antenna chlorophyll is an accurate indicator of energy flow. All of these statements may in fact be correct. However, in our view, the experimental bases for these postulates, though voluminous, are nevertheless, in our view, not commensurate with the importance of the propositions. We have therefore undertaken a comparison of the fluorescence emissions of three intact photosynthetic organisms with those of some model chlorophyll systems to address some issues that we feel are still unresolved.

Most of what is known or surmised about chlorophyll function in the primary light conversion events in green plants is derived from optical spectroscopy on intact living organisms or on (partially) functional fragments extracted from them. Even though such systems are considerably simplified relative to the intact organism, with the exception of crystalline reaction centers, they are still very complex. The precise relationships of the isolated thylakoid, reaction center preparation, or chlorophyll-protein complex to what is actually present in the intact 
organism is for the most part enigmatic. While optical spectroscopy is a powerful tool for characterizing excited state energy levels, the amount of structural information that can be extracted from optical data is distressingly small, and the assignment of the spectra is not at all a straightforward matter. In this communication, we have attempted to increase the information content of optical experiments by conducting parallel experiments on intact or fragmented photosynthetic systems, and on simple laboratory systems of well-defined composition and structure.

\section{Model Systems}

Porphyrins in various configurations have traditionally served as the models of choice for in vivo chlorophyll. This is not at all surprising, considering the important role porphyrins and porphyrin derivatives play in respiration, electron transfer agents, and enzymes. The biosynthesis of chlorophyll proceeds along the same pathway as that of the porphyrins present in hemoglobin, cytochrome $c$, and peroxidase. As chlorophyll once extracted from photosynthetic organisms is rather fragile, the much sturdier porphyrins have been used to study optical and other spectroscopic properties, in the expectation that information acquired on porphyrin systems will be applicable to the chlorophylls.

The spectroscopy of monomeric porphyrins and metalloporphyrins has received much attention, and the results have made important contributions to the spectroscopy of the chlorophylls. However, the applicability of monomeric porphyrins as models for chlorophyll is open to serious question. Monomeric porphyrins have optical, redox, solubility, and aggregation properties markedly different from those of the chlorophylls, and thus have only limited utility. However, model systems based on porphyrins covalently linked to other porphyrinş or to electron acceptors have played an important role in the study of electron transfer in photosynthesis. Particularly useful have been the models in which porphyrins have been linked to electron acceptors through rigid spacer molecules that position the donor and acceptor molecules at known fixed distances. Several excellent reviews of these model systems are cited in Ref. 4.

There are good reasons to suppose that the photosynthetic apparatus, both in green plants and bacteria, contains very little monomeric chlorophyll, and that aggregated chlorophyll is implicated in photoreaction center function 5 . The aggregation properties of porphyrins are very different from those of the chlorophylls, and therefore 
porphyrin models are at best rough approximations. Consequently, models in which covalently linked chlorophyll macrocycles are used have been developed, which more closely mimic the in vivo photoreaction center. These models consist of two pyrochlorophyllide, or better, chlorophyllide macrocycles, covalently linked through the hydroxyl groups of ethylene glycol (or longer chain diol) through the two propionic acid side chains of the macrocycles ${ }^{6,7}$. The basic factors involved in the self-assembly process have been identified from IR and NMR spectroscopic studies on chlorophyll by Closs, Katz, and co-workers.

We have considered model systems for photosynthesis research elsewhere; and will not discuss these further here. For our present purposes, we have used model systems that are self-assembled, that is, we have used Chla under conditions where self-assembly occurs to mimic both the primary electron donor in photosynthesis and the light harvesting antenna. . For the antenna, we have used a chlorophyll $a(\mathrm{Ch} l a)$ oligomer, (Chla), which is formed at ambient temperatures by a keto carbonyl interaction of one macrocycle and the central magnesium atom of another, i.e., keto $\mathrm{C}=\mathrm{O} \cdots \mathrm{Mg}$. In the absence of other nucleophiles, as in a nonpolar solvent such as n-octane, or methyl cyclohexane, aggregates containing twenty or more chlorophyll macrocycles are formed. This oligomer absorbs maximally at $680 \mathrm{~nm}$. For organisms that contain $\mathrm{ChB}$ as well as Chla, such as Chlorella vulgaris, an antenna model containing only Chla is obviously deficient. We have therefore also chosen for study two photosynthetic organisms that contain only Chla but which nevertheless evolve oxygen in photosynthesis. The modest red shift relative to monomeric Chl is indicative of only small $\pi-\pi$ interactions in the oligomer, despite its large size. A reasonable presumption is that the chlorophyll macrocycles in $(\mathrm{Ch} h)_{\mathrm{n}}$ are orthogonal to each other $^{(c)}$. This chlorophyll species appears to have a strongly diminished, if, in fact, any capacity at all, for fluorescence at room temperature.

To mimic the P700 of PSI we use in this paper a self-assembled Chb-ethanol/methyl cyclohexane ${ }^{10}$ system contains significant amounts of $700 \mathrm{~nm}$-absorbing species at low temperatures. Self-assembled systems can be formed that contain monomeric $\operatorname{Chl} a\left(\lambda_{\max } \sim 665 \mathrm{~nm}\right)$, oligomeric $(\mathrm{Chl} a)_{\mathrm{n}}\left(\lambda_{\max } \sim 678 \mathrm{~nm}\right)$, and species very similar to those formed by linked pairs in the folded configuration $\lambda_{\max } 698 \mathrm{~nm}$ ), depending on the temperature and the presence or absence of extraneous nucleophiles. These model systems, by virtue of the differences in the optical maxima, provide an excellent opportunity to study energy transfer by selective photoexcitation under well-defined conditions. 


\section{Photosynthetic Organisms}

We have chosen three photosynthetic organisms for our comparative fluorescence study. Chlorella vulgaris may be taken as the exemplar of higher green plants; its photosynthetic pigments consist of Chl and Chlb, and carotenoids. Tribonema aequale is a yellow-green alga (Xonthophyceae) that contains Chla and carotenoids. This organism evolves oxygen during photosynthesis; although it contains no $\mathrm{Ch} b$, and no phycobilins. Anacystis nichlons is a cyanobacterium (blue-green alga) that contains Chb, the phycobilins phycocyanin and phycoerythrin, and carotenoids. Photoselective excitation permits the preferential excitation of particular pigments in specific absorption bands, and the various pigment mixes in these three organisms provide good opportunities for the application of photoselective excitation. The general techniques for recording the fluorescence spectra are described in detail elsewhere ${ }^{10,11}$. Excitation was provided by a Molectron UV1000 nitrogen laser at $337 \mathrm{~nm}$ or by the output of a dye laser pumped by the Molectron.

\section{Results}

Figure IA shows composite room temperature absorption spectra of the various Chb species present in the self-assembled systems, and also spectra of $\beta$-carotene and the phycobilins, phycocyanin and phycoerythrin. Figure 1B shows the absorption spectrum of Anacystis nidulons. Indicated by Roman numerals are (approximate) regions for light absorption by different pigment systems. The selection of excitation wavelengths was partially based on the wavelength regions where the different pigments absorb, but primarily on the wavelengths of absorption of specific chlorophyll entities in vitro ${ }^{10,12}$. Reference 10 describes the parameters for selective excitation in detail,. As indicated in Figure 1A, excitation in the $430-440 \mathrm{~nm}$ and $650-670 \mathrm{~nm}$ regions preferentially excites monomer chlorophyll. Excitation near 450 and $690-700 \mathrm{~nm}$ can be used to preferentially excite chlorophyll species having the spectral properties of special pair chlorophyll (P700). In addition, if the in vitro systems contain species with the properties of chlorophyll oligomers, these can be excited by $678-681 \mathrm{~nm}$ light ${ }^{2}$.

Figure 2 shows the fluorescence spectra of the different pigment systems. Indicated are the emission wavelength maxima assigned to components of the in vivo photosystems PSI and PSII ${ }^{13-18}$. As can be seen in this figure, of the auxiliary pigments only phycocyanin shows significant emission in the PSI and PSII regions. 
Obviously, under some conditions emission from this (and perhaps related pigments) could complicate interpretation of in vivo fluorescence observations in cyanobacteria. The most important aspect of the data in Figure 2 is the significant emission in the PSI and PSII regions from a Chb-ethanol/methylcyclohexane self-assembled system both at room temperature and at $150 \mathrm{~K}$. For example, the band head near $683-685 \mathrm{~nm}$ is in the self-assembled system at the wavelength that has been assigned to the light harvesting Chl $a b$ protein complex (LHC) in PSII. We also note the red shift of the Chl $a$ emission in the PSI region that occurs with decreasing temperature. We have previously suggested that this phenomenon may reflect temperature dependent configurational changes in the selfassembled special pair type molecules that emit in this region ${ }^{0}$.

Figure 3 illustrates the effect of temperature and selective excitation on the fluorescence excited in the photosynthetic organisms we have used. In Table 1 we summarize in more detail the experimental observations, and in Table 2 we list the absorption and emission bands that have been assigned to components of the photosynthetic unit by various authors. These data, then, provide a basis for a discussion of possible relationships betweenin vitro and in vivo systems.

\section{Discussion}

Room temperature in vivo fluorescence emissions are generally very broad and ill-defined as can be judged from Figure 2. If we were to deconvolute these spectral bands into Gaussian components, the bands would clearly appear to be compound. This has been noted previously (cf. Litvin and Sineshchekov, ref. 19). What is important about this observation is the strong implication that there may be a large number of different species or different configurations of the same species that contribute to the emission in a particular wavelength region. It is, therefore, an oversimplification to talk about a limited number of in vivo states (i.e., PSI, PSII, etc.) as implied in the breakdown compiled from the literature in Table 2 . Lowering the temperature does not necessarily result in the appearance of sharply defined fluorescence spectra that can be associated with a limited number of states, although Rijgersberg and Amesz $z^{20}$ show clearly defined 685 and $695 \mathrm{~nm}$ bands in the $77 \mathrm{~K}$ fluorescence spectrum of $A$ nacystis nidulans excited with either 442 or $562 \mathrm{~nm}$ light. On the other hand, Satol' ${ }^{1}$ has also pointed out that it is often very difficult to detect a distinct $\mathrm{F} 695$ in the $77 \mathrm{~K}$ emission from the chloroplasts of higher plants and algae. It is clear 
from an examination of Table I and Figure 3 that the nature of the observed emissions depends strongly on both temperature and excitation wavelength. Although we do see emission band heads at 685 and $695 \mathrm{~nm}$ under specific excitation conditions, generally our emission curves are broad, which indicates that there are a number of emission bands in this wavelength region.

A very important question arises in connection with the observed emissions: how specifically can the emissions in a wavelength region be assigned to a particular species? For example, as indicated in Table 2 , there is a widely held view that the $685 \mathrm{~nm}$ fluorescence emanates from the light-harvesting Chb/ $b$ protein complex (LHC or CPII) of PSII. Satoh ${ }^{21}$ challenges this assignment with the observation that a prominent emission near this wavelength is observed in Tribonema and Anacystis under a variety of excitation conditions. Neither of these algae contains Chlb. Further, as indicated earlier and illustrated in Table 2, the emission wavelength for isolated lightharvesting $\mathrm{Chl} a b$ protein complexes (LHC) tends to be closer to $681-682 \mathrm{~nm}$ than to $685 \mathrm{~nm}$ (see also reference 21). Moreover, the isolated LHC's have absorption maxima near $671-672 \mathrm{~nm}$ and not at $680 \mathrm{~nm}$ as is characteristically observed for in vivo absorption (Table 2, note both PSI and PSII fractions). Although such small differences in absorption maxima are not necessarily highly significant, they must be taken into account in arriving at an assignment of the $685 \mathrm{~nm}$ emission to an emitting species of specific composition. Finally, we note that fluorescence maxima in the $680-690 \mathrm{~nm}$ spectral region can be observed under a number of conditions. For example, as indicated in Figure 2, fluorescence maxima near $685 \mathrm{~nm}$ can be obtained from Chl in a methylcyclohexane/ethanol solution under appropriate conditions of excitation wavelength and temperature. It has been suggested that in this case, the emitting species may be a $(\mathrm{Ch} b)_{n}$ oligomer coordinated to ethanol ${ }^{10}$. We have also seen weak emissions at 668 and $685 \mathrm{~nm}$ in Nujol mulls of $\mathrm{H}_{2} \mathrm{O}$-saturated octane. We observe a red shift of the emission wavelength for monomeric Chla in pyridine as the Chla concentration increases ${ }^{11}$, a phenomenon that can be related to self-absorption in concentrated solutions. These various observations suggest that it is, at present, not possible to make a definitive attribution to the source of the in vivo $680-690 \mathrm{~nm}$ fluorescence.

Questions also arise about the origins of both the $695 \mathrm{~nm}$ and $710-730 \mathrm{~nm}$ fluorescence. One view is that these arise from antenna chlorophylls in PSI and PSII, respectively ${ }^{3,14}$. It has been suggested ${ }^{15}$ that F695 arises from a species of chlorophyll in PSII, which forms on cooling to temperatures below $113 \mathrm{~K}$ and that the $710-730 \mathrm{~nm}$ 
fluorescence also arises from a species formed at low temperature in PSI. The latter species is designated by Satoh and Butler as $\mathrm{C} 75^{15}$. These authors consider that this species competes with P700 for the excitation energy in PSI. This interpretation is based on the assumption that there is no significant temperature effect on any of the fundamental rate constants for deexcitation by any pathway including nonradiative decay. The factor responsible for the large increase in fluorescence with decreasing temperature is presumed to be an increase in the concentration of C705 traps ${ }^{15,16}$. Butler et al. ${ }^{17}$ suggested that this species may be present at all temperatures but becomes more fluorescent at low temperatures. It would appear equally reasonable to assume that the increase in the fluorescence quantum yield could be associated with the formation of concentrations of P700 species in excess of those required to carry out the photochemistry. Thus, it appears unnecessary to assume that C705 is qualitatively different from P700. Both the increase in fluorescence yield and the increase in fluorescence lifetime $\mathrm{d}^{8,22}$ of PSI emitting fractions at low temperature are in accord with this view. We note that the in vitro experiments on self-assembly suggest the formation of a number of species or configurations that have $\mathrm{P} 700$ or special pair-like properties.

Implicit in the preceding discussion is the presumption that the low temperature PSI fluorescence arises from special pair type molecules, i.e. nucleophile-containing chlorophyll species. We know of no experimental observations indicating significant fluorescence from any chlorophyll species that are not monomeric or oriented by bifunctional nucleophiles. If, therefore, the antennae are oligomeric chlorophyll species, as is suggested by the absorption spectra, ${ }^{9}, 12$ then no antenna fluorescence should be observed. Thus, the observed fluorescence associated with PSII, F685 and F695, would appear to also involve chlorophyll molecules coordinated to a ligand.

As indicated in Table 1, excitation of intact Tribonema at $337 \mathrm{~nm}$ suspended in their growth medium at room temperature results in a broad fluorescence emission with maxima at $690 \mathrm{~nm}$ and $740 \mathrm{~nm}$. Cooling to $77 \mathrm{~K}$ narrows the fluorescence emission band and shifts the principal emission band to approximately $720 \mathrm{~nm}$, with a distinct shoulder in the $690 \mathrm{~nm}$ region. Warming the solutions to room temperature results in reversion to the original fluorescence band shapes and maxima.

When $450 \mathrm{~nm}$ radiation is used for excitation at room temperature the primary emission band from Tribonema is at $686 \mathrm{~nm}$ with a broad tail to the red. The primary band has a shoulder at approximately $673 \mathrm{~nm}$, near the wavelength expected for monomer Chl afluorescence. This is also the case for Anacystis (see Figure 3A). 
As indicated earlier, this emission cannot originate from a Chblb protein complex since these algae contain no Chl b. Cooling to $77 \mathrm{~K}$ results in spectral changes similar to those observed with $337 \mathrm{~nm}$ excitation, and the red maximum is near $715 \mathrm{~nm}$.

The results obtained with 672 or $681 \mathrm{~nm}$ radiation on Tribonema are particularly interesting. At room temperature the primary emission band is now observed at $693 \mathrm{~nm}$ (Figure 3D). The only other condition under which we see a band at this wavelength is at low temperature. When the excitation wavelength is $672 \mathrm{~nm}$, there is evidence for a shoulder in the $685 \mathrm{~nm}$ region. The primary emission band $(695 \mathrm{~nm})$ is relatively narrow, suggesting that the species responsible for the emission may be well defined in a structural sense. On cooling, the fluorescence emission is red shifted and broadened and at $148 \mathrm{~K}$, the primary emission is observed near $705 \mathrm{~nm}$. Obviously, the observations in this case are not consistent with the assumption that the F695 forms on cooling or that F695 is present, but nonfluorescent at room temperature (see prior discussion).

An important aspect of the present observations is that both the emission wavelengths and the shape of the emission bands depend on the excitation wavelength as well as on temperature. For example, in Figure $3 \mathrm{~A}$ and $3 \mathrm{C}$ we show room temperature fluorescence spectra for Anacystis and Chlorella excited by $450 \mathrm{~nm}$ radiation. At room temperature, the principal emission for both algae is at $685 \mathrm{~nm}$. The major difference is the shoulder near $650 \mathrm{~nm}$ in Anacystis resulting from phycocyanin emission. We contrast these results with those of Figure 3B, where Anacystis is excited by $627 \mathrm{~nm}$ radiation, i.e., in the absorption region of phycocyanin. In this case, at room temperature the principal emission is at $651 \mathrm{~nm}$ with a secondary maximum at $708 \mathrm{~nm}$. This suggests that the fluorescence is dominated by emission from phycocyanin. Such an assignment agrees with the observations of Dale and Teale ${ }^{23}$ who found that c-phycocyanin isolated from Anacystis has a fluorescence maximum at $651 \mathrm{~nm}$ with a secondary maximum near $710 \mathrm{~nm}$. The fact that we see such a strong phycocyanin emission at $651 \mathrm{~nm}$ but not the Chl $a$ maximum at $682-685 \mathrm{~nm}$ suggests that energy transfer from phycocyanin to Chla may be slow. If the pigment composition were homogeneous and the energy transfer fast, no dependence of the fluorescence on the excitation wavelength would be observed.

The fluorescence intensity of phycocyanin at wavelengths longer than $670 \mathrm{~nm}$ is much less than that of Chb 
when the pure pigments are excited at their respective absorption maxima (Figure 2A). A comparison of these spectra with the room temperature spectra of Figure $3 \mathrm{~A}$ and $3 \mathrm{~B}$ shows that there must be a significant contribution by Chla to the Anacystis fluorescence at wavelengths longer than $670 \mathrm{~nm}$. At low temperature this comparison strongly suggests that the fluorescence maxima at 682 and $715 \mathrm{~nm}$ as well as the shoulder in the $690-700 \mathrm{~nm}$ region (Figure 3B) are contributed by Chla species. The marked difference in the fluorescence spectra of $A$ nacystis obtained with different excitation wavelengths suggests that in addition to possibly slow energy transfer steps there may be a significant heterogeneity in the pigment distribution. Such a heterogeneity, coupled with a slow rate of excitation energy transfer between the different structures would be consistent with the observed dependence of the fluorescence wavelengths on excitation frequency. This interpretation is the same as that advanced to explain a similar phenomenon in vitro chlorophyll solutions containing a mixture of species ${ }^{10}$.

\section{Concluding Remarks}

Fluorescence emission from the algae Tribonemaaequale, Anacystis nidulons, and Chlorellavulgaris have been recorded as a function of excitation wavelength and temperature. Light emission from the algae are found to depend on both wavelength and temperature. The fluorescence data suggest that there are slow steps in energy transfer between pigment systems in these algae. We observe considerable similarity in the effects of excitation frequency and temperature on the fluorescence of intact algae and that of suitably chosen in vitro chlorophyll systems. The parallelism in behavior between in vivo and in vitro systems suggest that self-assembly processes result in the formation of new chlorophyll species not present at room temperature in photosynthetic organisms as a result of lowering the temperature, and that as a consequence, interpretation of low temperature observations in terms of the photosynthetic species present at ordinary temperatures may be open to question.

\section{Acknowledgement}

Work performed under the auspices of the Office of Basic Energy Sciences, Division of Chemical Sciences, U.S. Department of Energy under contract W-31-109-ENG-38. 


\section{References}

1. (a) Deisenhofer, J.; Epp, O.; Miki, K.; Huber, R.; Michel, H.Nature 1985, 318, 618-624; (b) Deisenhofer, J.; Michl, H.; Huber, R. TIBS 1985, 10, 243-248; (c) Chang, C.-H.; Tiede, D.; Smith, U.; Norris, J.; Schiffer, M. FEBS 1986, 205, 82-86; (d) Allen, J.P.; Feher, G.; Yeates, T.O.; Komiya, H; Rees, D.C. Proc. Natl. Acad. Sci. U.S.A. $1987,84,6162-6166$.

2. Cf. Gouterman, M; Rentzepis, P.M; Straub, KD. Porphyrins Excited State Dynamics, A.C.S. Monograph No. 321, American Chemical Society, Washington, D.C. 1986, 371pp.

3. (a) Sessler, J.L.; Capuano, V.L. Angew. Chem. Intl. Ed. Engl. 1990, 29, 1134-1137; (b) Harriman, A.; Kubo, Y.; Sessler, J.L. J. Am. Chem. Soc. 1992, 114, 388-390; (c) Gust, D.; Moore, T.A.; Moore, A.L.; Makings, L.R.; Seely, G.R; Ma, X.; Trier, T.T.; Gao, F. J. Am. Chem. Soc. 1988, 110, 7567-7569.

4. (a) Gust, D.; Moore, T.A. In Topics in Current Chemistry, 1991 Vol. 159, pp. 104-151; (b) Gust, D.; Moore, T.A.; Moore, A.L.; Devadoss, C.; Liddel, P.A.; Hermant, R; Nieman, R.A.; Demanche, L.J.; DeGraziano, J.M.; Gouni, I. J. Am. Chem. Soc. 1992, 114, 3590-3603; (c) Gust, D.; Moore, T.A.; Moore, A.L. Accounts of Chemical Research 1993, 23, 198-205; (d) Gust, D; Moore, T.A.; Moore, A.L.; Liddell, P.A.Methods in Enzymology, 1992, Vol. 213, pp. 87-100; (e) Gust, D.; Moore, T.A. Science 1989 244, 35-41; (f) Gust, D.; Moore, T.A. $A d v$. Photochem. 1991, 16, 1-65; (f) Wasielewski, M.R. In Chlorophylls, Scheer, H., Ed., RC Press: Boca Raton, 1991, pp. 270-286; (g) Schmidt, J.A.; McIntosh, A.R.; Weedon, A.C.; Bolton, J.R.; Connolly, J.S.; Hurley, J.K; Wasielewski, M.R. J. Am. Chem. Soc. 1988, 110, 1733-1740; (h) Wasielewski, M.R. Chem. Rev. 1992, 92, 435461; (i) Wasielewski, M.R. In Metal Ions in Biological Systems, Sigel, H.and Sigel, A. Eds, Marcel Dekker, Inc.: New York, 1991, Chapter 11, pp. 361-430; (j) Wasielewski, M.R. In The Photoreaction Center, Vol. II, Norris, J.R; Diesenhofer, J. Eds. Academic Press: San Diego, 1993, pp. 465-511; (k) Wasielewski, M.R. In Photoinduced Electron Transfer, Part A, Fox, M.A.; Chanon, M., Eds.; Elsevier: Amsterdam, 1988, pp. 161-206 
5. (a) Katz, J.J;; Ballschmiter, K; Garcia-Morin, M.; Strain, H.H.; Uphaus, R.A. Proc. Natl. Acad. Sci. U.S.A. 1968, 60, 100-107; (b) Norris, J.R; Uphaus, R.A.; Crespi, H.L.; Katz, J.J. Proc. Natl. Acad. Sci. U.S. 1971, 625-628; (c) Katz, J.J.; Norris, J.R. Current Topics in Bioenergetics 1973, 5, 51-75.

6. (a) Boxer, S.G.; Closs, G.L. J. Am. Chem. Soc. 1976, 98, 5406-5408; Wasielewski, M.R.; Smith, U.H.; Cope, B.T.; Katz, J.J. J.Am. Chem. Soc. 1977, 99, 4172-4173: Boxer, S.G.; Bucks, R.R. J. Am. Chem. Soc. 1982, 104, 340-343; Wasielewski, M.R.; Studier, M.H.; Katz, J.J. Proc. Natl. Acad. Sci. U.S.A.-1976, 4282-4286.

7. (a) Krasnovsky, A.A. In Progress in Photosyntheis Research Metzner, H., Ed., Lichtenstein, Munich, 1968, 763-776; Krasnovsky, A.A.; Bystrova, M.I. BioSystems 1980, 181-195; (c) Katz, J.J.; Ballschmiter, K. Angew. Chem. Intl. Ed. Engl. 1968, 7, 286-287.

8. (a) Closs, G.L.; Katz, J.J.; Pennington, F.C.; Thomas, M.R.; Strain, H.H. J. Am. Chem. Soc. 1963, 85, 38093821. (b) Katz, J.J.; Closs, G.L.; Pennington, F.C.; Thomas, M.R.; Strain, H.H. J. Am. Chem. Soc. 1963, 38013809; (c) Katz, J.J.; Dougherty, R.C.; Boucher, L.J.; In The Chlorophylls, Vernon, L.P.; Seely, G.R., Eds., 1966, Chop. 7, 185-251; (d) Katz, J.J. Developments in Applied Spectroscopy, 1968, 6, 201-218; (e) Katz, J.J. In Inorganic Biochemistry, Vol. II, Eichhorn, G., Ed. Elsevier: Amsterdam, 1973, pp. 1022-1066.

9. (a) Katz, J.J.; Hindman, J.C. In Proc.Fifth International Photosynthesis Congress, Akoyonglu, G., Ed., Balaban International Science Services, Philadelphia, 1981, Vol. 1, 193-203; (b) Katz, J.J.; (b) Hindman, J.C.; In Biological Events Probed by Ultrafost Laser Spectroscopy, Alfano, R.R, Ed., Academic Press, New York, 1982, pp. 119-155;

(c) Katz, J.J.; Norris, J.R; Shipman, L.L. In Brookhaven Symposia in Biology 1976, No. 26, 16-55; (d) Katz, J.J.; Shipman, L.L.; Norris, J.R In Chlorophyll Organization and Energy Transfer in Photosynthesis, Ciba Foundation Symposium 61 (New Series), Excerpta Medica: Amsterdam, pp. 1-34. (e) Katz, J.J. In Light Induced Charge Separation in Biology and Chemistry, Gerischer, H; Katz, J.J., Eds. Berlin-Dahlem Konferenzen, Verlag Chemie: Weinheim-New York, 1979, pp. 331-359. 
10. (a) Yuen, M.J.; Shipman, L.L.; Katz, J.J.; Hindman, J.C. Photochem. Photobiol. 1982, 36, 211-222;

Shipman, L.L.; Cotton, T.M.; Norris, J.R.; Katz, J.J. Proc. Notl. Acad. Sci. U.S.A. 1976, 73, 1791-1794.

11. Yeun, M.J.; Shipman, L.L.; Katz, J.J.; Hindman, J.C. Photochem. Photobiol. 1980, 32, 281-296.

12. 12. Shipman, L.L.; Cotton, T.M.; Norris, J.R.; Katz, J.J. J. Am. Chem. Soc. 1976, 98, 8222-8230.

13. Butler, W.L.; Kitajima, N. Proc. Third International Congress on Photosynthesis, Avron, M., Ed., Elsevier, Amsterdam, 1974, pp. 13-44.

14. Butler, W.L.; Strasser, R.J. Proc. Natl. Acad. Sci. U.S.A. 1977, 74, 3382-3365.

15. Satoh, K; Butler, W.L. Biochim. Biophys. Acta, 1978, 502, 103-110.

16. Butler, W.L. Ann. Rev. Plant. Physiol. 1978, 29, 345-378.

17. Butler, W.L.; Tredwell, C.J.; Malkin, R.; Barber, J. Biochim Biophys. Acta 1979, 545, 309-315.

18, Searle, G.F.W.; Barber, J.; Harris, I.; Porter, G.; Tredwell, C.J.; Biochim. Biophys. Acta, 1977, 459, $390-401$

19. Litvin, F.R; Sineshchekov, V.A. In Bioenergetics in Photosynthesis, Govindjee, Ed., Academic Press, New York, 1975, Chopter 12, pp. 619-661.

20. (a) Rijgersberg, C.P.; Amesz, J. Biochim Biophys. Acta 1980, 593, 261-271; (b) Amesz, J.: Rijgersberg, C.P. In Photosynthesis III, Structure and Molecular Organization of the Photosynthetic Apparatus, Akoyunoglou, G. Ed., Balaban International Science Services, Philadelphia, PA. 1981, pp. 739-747; (c) Kramer, HJ.M; 
Westerhuis, W.H.J.; Amesz, J. Physiol. Veg. 1985, 23, 535-543; (c) Amesz, J. Progress in Botany, 1987, Vol. 47, Springer Verlag, Berlin, pp.87-102.

21. Satoh, K. FEBS Lett., 1980, 110, 53-56.

22. Herve, G.; Paillotin, G.; Thiery, J. J. Chem. Phys. 1975, 72, 761-766.

23. Dale, RE.; Teale, F.W.J. Photochem. Photobiol. 1970, 12, 99-117.

24. Thornber, J.F.; Markwell, J.P.; Reiman, S. Photochim. Photobiol. 1979, 29, 1205-1216.

25. Brown, J.S. In Bioenergetics of Membrones, Packer, L., Ed., Elsevier/North Holland, Amsterdam, 1977, pp. 297-304.

26. Kitajima, M; Butler, W.L. Biochim. Biophys. Acta 1975, 408, 297-305. 


\section{Figure Legends}

Figure 1. Absorption spectra.

A. Pigments

-.- Chl $a$ in ethanol-methylcyclohexane at $298 \mathrm{~K}$. Chl $a$ in ethanol-methylcyclohexane at $150 \mathrm{~K}$. (Self assembled special pair.)

Chl $a=2.25 \times 10^{-3} \mathrm{M}$.

Ethanol $=3.6 \times 10^{-2} \mathrm{M}$.

$\mathrm{x}-\mathrm{x}$ B-carotene in octane (Absn. scale not comparable with $\mathrm{Chl}$ a).

Phycoerythrin in $0.1 \mathrm{M}$ phosphate buffer.

$\mathrm{pH}=5.9$ (Absorption scale not comparable with $\mathrm{Chl} a$ ).

… Phycocyanin in $0.1 \mathrm{M}$ Na phosphate buffer.

$\mathrm{pH}=5.9$ (Absorption scale not comparable with $\mathrm{Chl} a$ ).

B. Anacystis nidulans

Anacystis $\left(\mathrm{H}_{2} \mathrm{O}\right)$, suspended in glycerol, $298 \mathrm{~K}$.

$\downarrow$ Wavelengths for selective excitation.

- $450,696 \mathrm{~nm}$, "self-assembled" special pairs.

$620 \mathrm{~nm}$, phycocyanin.

$660 \mathrm{~nm}$, monomer Chl $a$.

$670,680 \mathrm{~nm}$, oligomer (antenna) Chl $a$.

I. Chlorophyll $a$ Soret.

II,III. Auxiliary pigments.

IV. Chlorophyll $a, \mathrm{Q}_{\mathrm{y}}$ region. 
Figure 2. Fluorescence spectra of pigments.

A. $298 \mathrm{~K}$, fluorescence scales for different pigments not comparable.

-... Phycoerythrin in $0.1 \mathrm{M}$ Na phosphate buffer.

$\mathrm{pH}=5.9, \lambda_{\text {exc }}=337 \mathrm{~nm}$.

Phycocyanin in $0.1 \mathrm{M} \mathrm{Na}$ phosphate buffer.

$\mathrm{pH}=5.9, \lambda_{\text {exc }}=627 \mathrm{~nm}$ (Note Figure 1B).

$\mathrm{x}-\mathrm{x}$ Chlorophyll $a$ in ethanol/methylcyclohexane.

$\lambda_{\text {exc }}=672 \mathrm{~nm}$, similar spectra obtained with $681 \mathrm{~nm}$ excitation.

PSII, PSI, $\downarrow$ Fluorescence regions assigned to Photosystems I and II in vivo, see text.

B. Phycocyanin in $0.1 \mathrm{M} \mathrm{Na}$ phosphate buffer.

$\mathrm{pH}=5.9,130 \mathrm{~K}, \lambda_{\text {exc }}=627 \mathrm{~nm}$.

$x-x$ Chlorophyll $a$ in ethanol $/$ methylcyclohexane, $150 \mathrm{~K}, \lambda_{\text {exc }}=672 \mathrm{~nm}$. Similar spectrum obtained with $681 \mathrm{~nm}$ excitation.

Figure 3. Fluorescence spectra of algae. $\mathrm{S}$ indicates a shoulder.

A. Anacystis $\left(\mathrm{H}_{2} \mathrm{O}\right)$ suspended in growth medium.

$\lambda_{\text {exc }}=448-451 \mathrm{~nm}$.

$290 \mathrm{~K}$.

… $77 \mathrm{~K}$.

B. Anacystis $\left(\mathrm{H}_{2} \mathrm{O}\right)$, growth medium.

$\lambda_{\text {exc }}=627 \mathrm{~nm}$.

$298 \mathrm{~K}$.

… $77 \mathrm{~K}$

C. Chlorella $\left(\mathrm{H}_{2} \mathrm{O}\right)$, glycerol suspension.

$\lambda_{\text {exc }}=450 \mathrm{~nm}$.

$298 \mathrm{~K}$.

… $77 \mathrm{~K}$. 
D. Tribonema $\left(\mathrm{H}_{2} \mathrm{O}\right)$, culture medium.

$$
\begin{aligned}
& \lambda_{\text {exc }}=672 \mathrm{~nm}\left(\lambda_{\text {exc }}=680 \mathrm{~nm} \text {, also shows } 693.4 \mathrm{~nm} \text { band }\right) \\
& 298 \mathrm{~K}
\end{aligned}
$$

… $77 \mathrm{~K}$ 
Table 1. Emission of Intact in vivo Systems obtained by Selective Excitation

\begin{tabular}{|c|c|c|c|}
\hline Species (Pigments) & $\lambda_{\mathrm{ex}}(\mathrm{nm})$ & Temp K & $\begin{array}{c}\text { Emission } \lambda(\mathrm{nm}) \\
(\mathrm{sh}) \text { designates shoulder }\end{array}$ \\
\hline $\begin{array}{l}\text { Tribonema } \\
\qquad \begin{array}{l}(\mathrm{Chl} a) \\
\text { (carotenoids) }^{\mathrm{a}}\end{array}\end{array}$ & $\begin{array}{l}337 \\
450 \\
650,661 \\
672\end{array}$ & $\begin{array}{c}298 \\
77 \\
298 \\
77 \\
298 \\
298 \\
77\end{array}$ & $\begin{array}{l}690,740 \\
720,690 \text { (sh) } \\
686,673 \text { (sh) } \\
715 \\
687,690-700,720 \\
695,685 \text { (sh) } \\
705 \text { (very broad) }\end{array}$ \\
\hline $\begin{array}{l}\text { Anacystis nidulans } \\
\text { (Chl a) } \\
\text { (carotenoids) }^{\mathrm{a}} \\
\text { (xanthophylls) }^{\mathrm{b}} \\
\text { (phycobilins) }^{\mathrm{c}}\end{array}$ & $\begin{array}{l}337 \\
450 \\
500 \\
629 \\
640 \\
681^{d} \\
685^{d} \\
696^{d}\end{array}$ & $\begin{array}{c}298 \\
77 \\
298 \\
77 \\
298 \\
77 \\
298 \\
77 \\
298 \\
77 \\
77 \\
298 \\
77 \\
298 \\
77\end{array}$ & $\begin{array}{l}653,700 \\
653,694,706 \text { (red tail) } \\
685,651 \text { (sh) } \\
715 \\
651,684,580(\mathrm{sh}) \\
715,650,586(\mathrm{sh}) \\
651,708 \\
653,683,715 \\
700 \text { (broad), } 655(\mathrm{sh}) \\
715,650(\mathrm{sh}), 755 \\
695,710 \text { (tail to red) } \\
? \\
705-715 \\
? \\
\text { So me fluorescence } \\
\text { possible above } 730 \mathrm{~nm}\end{array}$ \\
\hline $\begin{array}{l}\text { Chlorella vulgaris }^{\mathrm{e}} \\
\text { (Chl } a) \\
(\mathrm{Chl} b) \\
\text { (carotenoids) }^{\mathrm{a}} \\
\text { (xanthophylls) }^{\mathrm{b}}\end{array}$ & $\begin{array}{l}337 \\
450 \\
500 \\
627 \\
660 \\
685^{\mathrm{d}} \\
696^{\mathrm{d}}\end{array}$ & $\begin{array}{c}298 \\
77 \\
298 \\
77 \\
298 \\
77 \\
298 \\
77 \\
298 \\
77 \\
298 \\
77 \\
298 \\
\\
77\end{array}$ & $\begin{array}{l}685 \text { (tail to red) } \\
722,684 \\
686,730 \\
684,695,713 \\
685 \\
715,685 \text { (sh) } \\
685,715 \\
685 \\
685,712 \\
\text { tail from laser to } 790 \mathrm{~nm} \\
723 \\
\text { some fluorescence with } \\
\text { laser band } \\
723\end{array}$ \\
\hline
\end{tabular}




\section{Footnotes for Table 1}

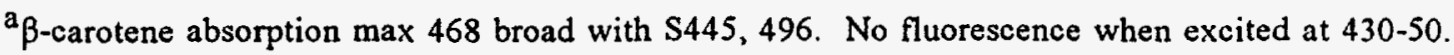

${ }^{b}$ Xanthophylls (oxycarotenes), like carotenes, absorption $430-500 \mathrm{~nm}$, weakly fluorescent.

${ }^{c}$ According to Rijgersberg and Amesz ${ }^{20}$, the $650 \mathrm{~nm}$ emission in Anacystis involves two bands contributed by Cphycocyanin and allophycocyanin. Bands at $650 \mathrm{~nm}$ and $680 \mathrm{~nm}$ obtained from isolated phycobilisomes are ascribed to allophycocyanin and allophycocyanin $B$, respectively.

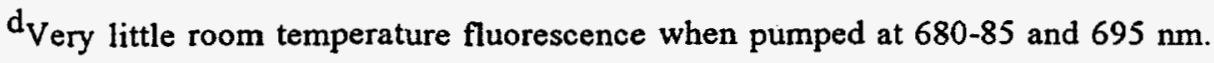

${ }^{\mathrm{e}}$ The Chlorella used for the fluorescence studies were suspended in glycerol.

$\mathrm{f}_{\text {The }} 694$ and $706 \mathrm{~nm}$ emissions represent band heads in a very broad emission spectrum with a shallow minimum at $700 \mathrm{~nm}$. 
Table 2. Assignments of Absorption and Emission Bands for Photosynthetic Unit Components

\begin{tabular}{|c|c|c|c|}
\hline & Temp K & Absorption $\lambda(\mathrm{nm})$ & Emission $\lambda(\mathrm{nm})$ \\
\hline PSI Fraction Composite ${ }^{a}$ & $\begin{array}{r}298 \\
77\end{array}$ & 437,680 & $\begin{array}{l}682(730-740)^{\mathrm{b}} \\
730,680^{\mathrm{b}}\end{array}$ \\
\hline CPI chlorophyllin & $\begin{array}{c}298 \\
77\end{array}$ & $673-77,490^{d}$ & $\begin{array}{l}685,725,735(\mathrm{sh})^{\mathrm{e}} \\
685,695,705,720,735\end{array}$ \\
\hline PSI Fractiong & $\begin{array}{c}298 \\
77\end{array}$ & 437,680 & $\begin{array}{l}682(730-740)^{b} \\
730,735\end{array}$ \\
\hline $\begin{array}{l}\text { PSI, Antenna and } \\
\text { Reaction Center } 8\end{array}$ & 77 & 681 & $730-5^{\mathrm{g}, \mathrm{h}}$ \\
\hline $\begin{array}{l}\text { PSII Fraction } \\
\text { LHC, Chl } a / b\end{array}$ & 298 & $\begin{array}{l}436,471 \\
653,680\end{array}$ & $682(730-740)$ \\
\hline Protein $^{a}$ & 77 & & $683-4,695-6$ \\
\hline Antenna, trap ${ }^{g}$ & 77 & $\begin{array}{l}650,677 \\
670(\mathrm{sh})\end{array}$ & $694-5^{h}$ \\
\hline $\begin{array}{l}\text { CPII chlorophyllin }{ }^{\mathrm{i}} \\
\text { Chl a/b chlorophyllin }\end{array}$ & 298 & $\begin{array}{l}652,672 \\
475\end{array}$ & 681 \\
\hline
\end{tabular}

${ }^{a}$ Searle et al. ${ }^{18}$

${ }^{b}$ Very weak emission.

$\mathbf{c}_{\text {Thornber et al. }}{ }^{24}$

$\mathrm{d}_{\beta \text {-carotene-chlorophyllin, Thornber ẹt al. }}{ }^{24}$

e shoulder, sh

$\mathrm{f}_{\text {Emission data from Brown }}{ }^{25}$, both $290 \mathrm{~K}$ and $77 \mathrm{~K}$. At $77 \mathrm{~K}, 685 \mathrm{~nm}$ band decreases relative to $695 \mathrm{~nm}$ band and amplitude bands $705,720,735$ variable with different preparations.

$\mathrm{g}_{\mathrm{Kitajima}}$ and Butler ${ }^{26}$. Assignment of absorption wavelength based on excitation spectra.

$\mathrm{h}_{\text {Butler }}{ }^{16}$.

${ }^{i}$ CPII chlorophyllin - light harvesting $\mathrm{Chl} a / b$ protein complex in PSII. May be complex mixture including oligomeric forms. See reference (6). 
I әxnธTุษ

ABSORTION (ARBITRARY SCALE)

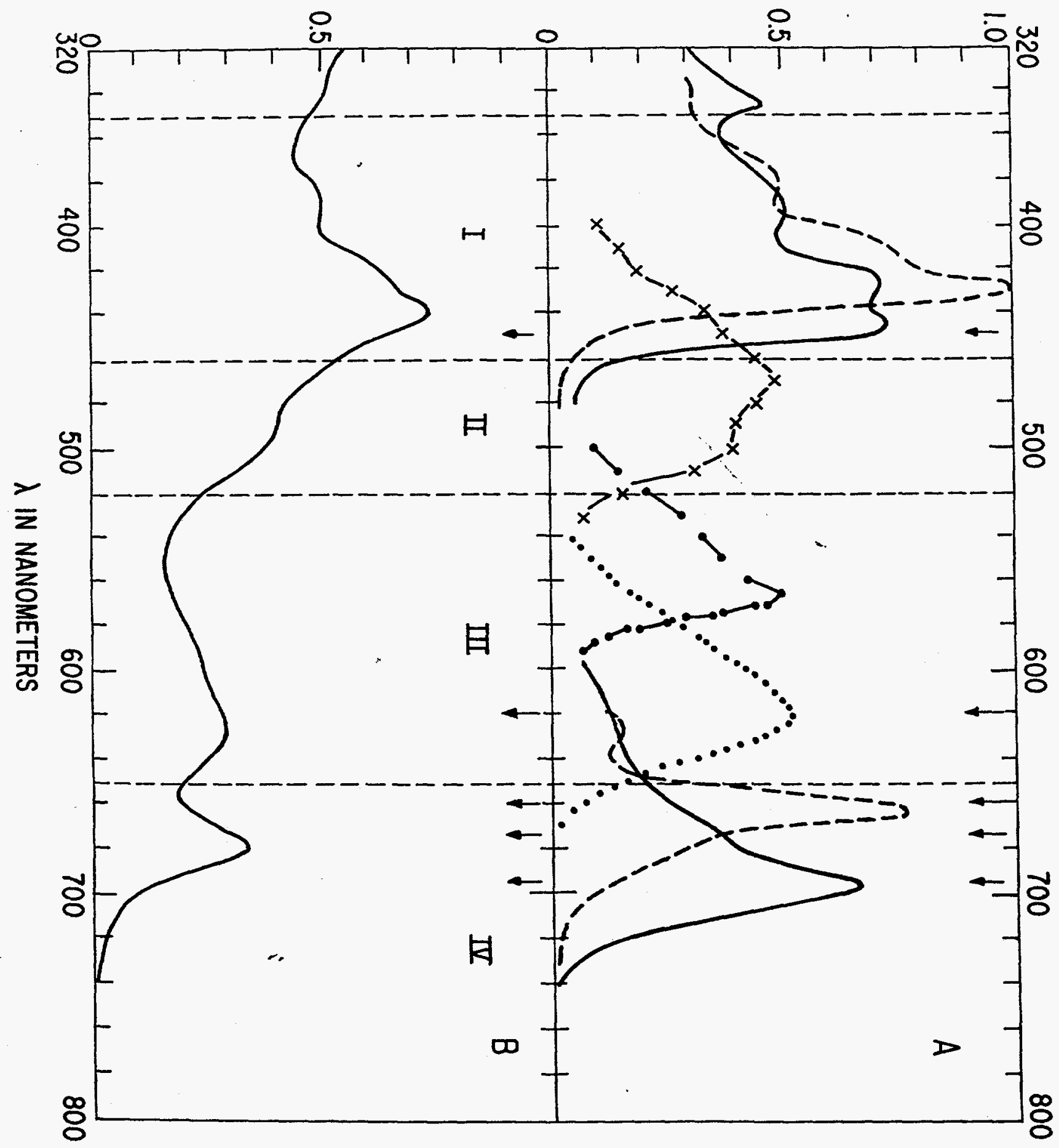




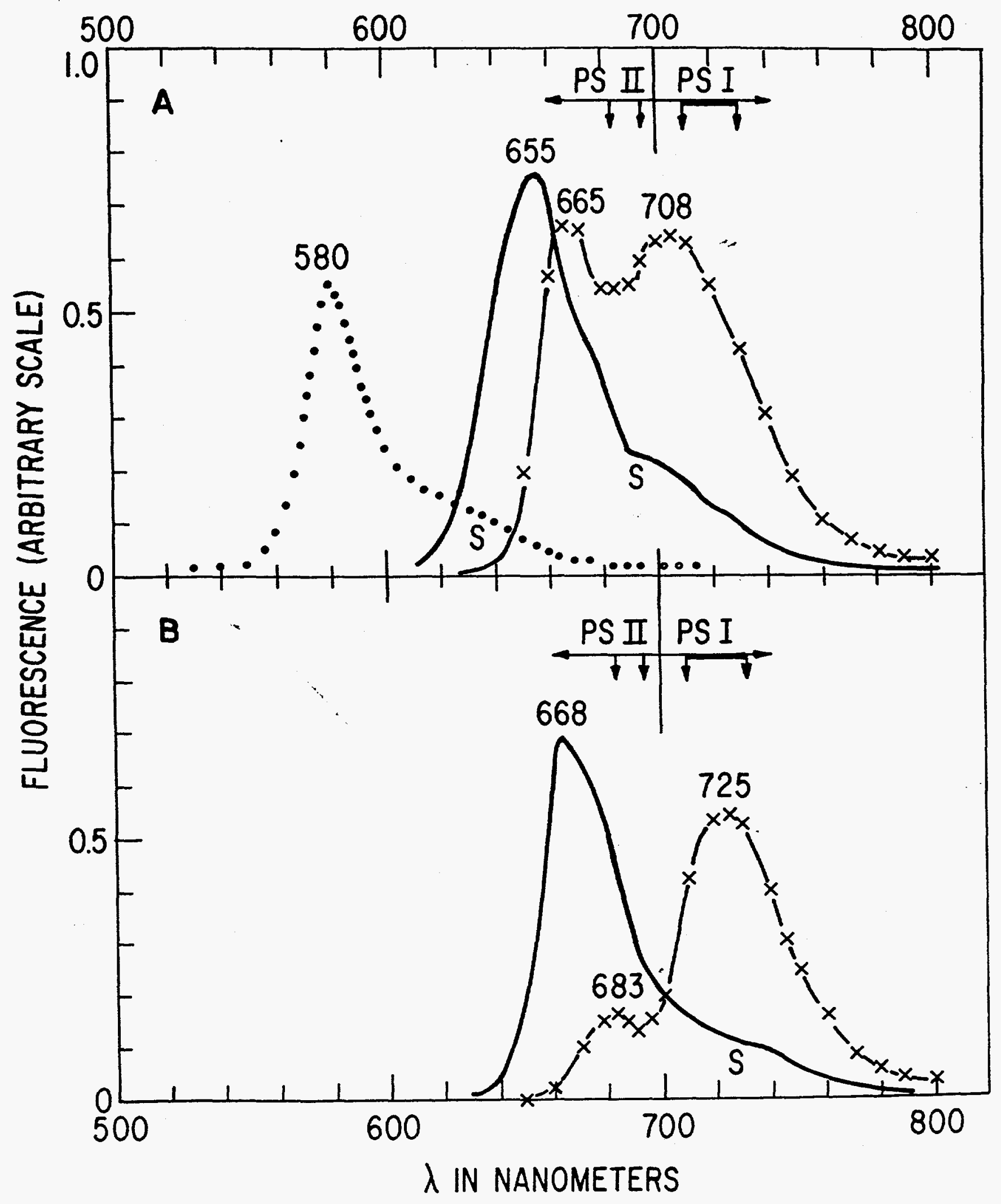




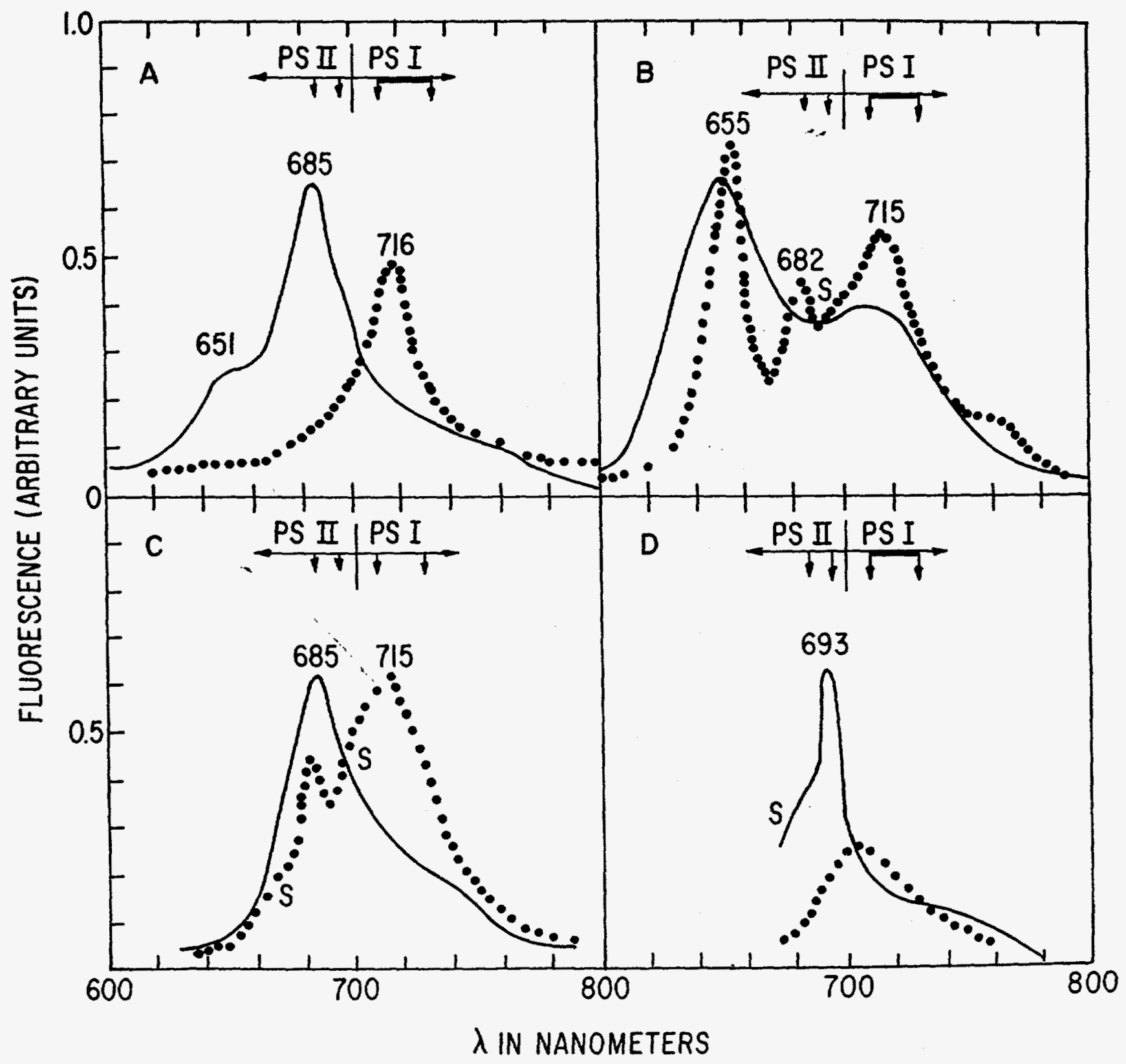

